\title{
Teaching Plane Pictures Design Base on Visual Thinking
}

\author{
Xu Wenyi and Li Jian
}

\begin{abstract}
The "plane picture" means two-dimensional image or the graph. In this paper author discussed visual thinking and expounded on the memory knowledge formed by visual thinking and plane pictures or plane picture teaching software. Author points out plane picture is the most important visual media and author thinks that plane picture design from the perspective of the visual thinking depends on the physiological and psychological cognition for audience and student. In this paper, the author also think and analyze that visual media design to plane pictures, especially to teaching plane picture design needs enough experience of visual thinking and good ability of visual thinking for designer. Before designing plane picture, especially for teaching plane picture designing, every designer should have visual thinking consider or design which is the researching aim for this paper.
\end{abstract}

Index Terms-Perception, image, visual thinking, plane picture, design.

\section{INTRODUCTION}

From a physical point of view, see, hear, touch, smell is a major organs of people's perception of nature. So-called consciousness is physiological organ "perception" and psychological "cognitive" and understanding for the outside things. The perception of the human body is a very complicated physiological and psychological phenomenon that is why the consciousness of people include thinking activity.

"Visual perception", "Hear consciousness" is one of the most important sense of human, is a major channel of human sense to know the outside world things. Perception plays an important role of creative thinking, this paper mainly discusses the rational function of visual perception. American art psychologist Rudolph Arne Haim proved with a large number of facts in his book "Art and Visual Perception" that all perceptions contains the thinking mode of perception, all reasoning contains intuition, every observing thing contains the creation. In his monograph "visual thinking", he not only further expounds the rational function of visual perception, but also to clarify the important role and significance of the "visual images" in the general thinking activity, especially of creative thinking activity [1].

Above "Visual Images "includes "meaning and image" and the "meaning" of them is the inner abstract thoughts, and "image" is the external specific object. "Meaning" comes from the heart and is expressed by "image" and image actually

Manuscript received October 30, 2015; revised May 9, 2016.

$\mathrm{Xu}$ Wenyi is with the Faculty of Media and Information Engineering in Yunnan Open University, Kunming, Yunnan, China (e-mail: 51880440@qq.com).

Li Jian was with the Faculty of Finance in Oxbridge College, Kunming University of Science and Technology, Kunming, Yunnan, China (e-mail: joyajoy@126.com). is the anchorage of meaning. The understanding of the ancients, so to speak, is today, we often say the relationship and function of physiology and psychology. The some feeling to world things for someone will be gave a bailment of the selected representational, make it into one of the representational (through perception) some kind of feeling even includes some kind of emotional color.

American psychologist R. H. McKim is the first one of the formal use for the concept of visual thinking.According to his research, his generalization and defined to the concept is a unique. He noted, visual thinking is carried out with the help of the three kinds of visual image: one is "seen" image (watch); the second one is we think with the window of the soul(imagine); the third one is we painted the structure, random drawing or painting(structure).Although visual thinking can be mainly appear in the back and forth of "seeing", or only in the imagination, or a lot in the use of pencil and paper, author considers that there is not better visual thinking if there is less thinking experience. The experience of visual thinking comes from the three images, e.g. seeing, imagination and structure drawing and their interaction. Maybe, the expression of aesthetic intuition thinking, imagery thinking, intuition thinking, is more appropriate. R. H. McKim's biggest characteristic about the visual thinking definition is operational, can be seen as an operational definition of the concept of visual thinking [2].

Based on thinking, the definition of general psychology and Arne Haim, R. H. McKim about the interpretation of the visual thinking [2], we can form a basic understanding to mental activity of visual thinking, e.g. visual thinking is based on visual organ's reaction under external stimuli. The visual organ transmits external stimulation in form of the signal to the brain, step by step and forms some visual image, which becomes direct materials of the visual thinking. Visual thinking is a psychological process on the basis of human visual perception that refers to analyses visual imagery, generalization, processing and finishing, to find meaning and to achieve a certain purpose.

Visual thinking is a kind of positive reason activity and it's also a kind of creative grasp for reality .Creative activities of visual thinking is made up in the form of alternating and changing throughout with the help of image, in terms of observation, imagination, graphic structure, etc. .Visual thinking is a unique features of the brain's right hemisphere and the internal mechanism of the creativity and is the result of division cooperation and interaction of left and right brain. The plane picture designer has to consider above theory so that achieve better design effect and application effect especially in teaching software design [3].

\section{The Plane Picture Design And Visual Thinking AND}




\section{VISUAL EXPERIENCE}

Visual media is a kind of media to accept information through the visual way, such as the pictures, symbols, newspapers, magazines, brochures, etc. According to accept the category and application of information, visual media can be divided in different classification, for example, application classification, teaching function classification of visual media such as texts, pictures, multimedia, etc.[4]. All media which transmits information media through the visual sense belongs to visual media. Visual media is the most abundant source of information. All visual image of object offering a perception by the human visual system is called image .In fact, text, pictures are finally appeared in the form of image. Because the different ways of computer representation, processing, display methods, generally they are considered as different media. Plane picture is one of the most widely visual media used in the education and teaching.

For example, for acoustical teaching, acoustical wave propagation is described usually by plane picture and there will be different teaching effect with different visual effect and different visual effect comes from visual thinking.

For visual thinking, Imagine of plane picture faced by visual thinking is the objective, authentic, specific picture images and reflects the universal realistic significance and broad Association's teaching purpose and aesthetic values and it's easy to produce and form the image thinking, which also known as the visual image thinking.

Further abstract thinking is often based on visual image thinking. That are both rational and exaggerated, without being limited by the object light, color changing and the people's thinking and reverse thinking, harmonious and disharmonious and are perfectly applicate in limit. Above the result produced the visual stimulation, exciting, Association in visual sense, namely its visual thinking formed. This is the plane picture or plane picture teaching software is to achieve the effect.

The knowledge as a kind of special information should be kept in brain by memory, reappear or recognition. Only if the knowledge is kept in your mind it can be extracted when you need to recall, knowledge can be also called knowledge achieved by learners themselves. So the learning process is also regarded as effectively memorize knowledge process. Experiments show that the easy sequence of media to human memorization is: pictures, sounds, words and number. Pictures, special plane picture can give an expression to a better intuitively imaginal memory .So the intuitive plane picture can be apply to education and teaching .The knowledge will be presented vividly so that the students can memory knowledge effectively on the basis of the understanding it under helping of picture medium and teacher's guide [5].

Seeing is believing! And after that thinking, knowledge and member! Sometime it is difficult to describe something, some progress or some knowledge by language. For example how to describe a tiger looks like to someone who has never met one to a child? Telling "a large feline of forests" "having a tawny coat with black stripes" cannot be better than designing and showing a color tiger picture which will gives the child an visual thinking and some knowledge about tiger. Plane picture for teaching is able to analyze, synthesize, abstract, summarize knowledge so that the knowledge to be memory and form the typical image. Most people can cognize and further understand it when they see the plane picture. It is noteworthy that visual thinking is mainly derived from visual experience.

Sense of vision plays an important role in guiding behavior of people. Impression of the image of things get through eyes are distinguished to different types and levels of sensory stimulation, information obtained from visual account for the vast majority of the outside world. Visual experience is memory that people catch through the visual sensory. Those memories are not pure sensory feelings because with the growth of people more complex emotional elements and even their own thinking rational elements are changing. It can be said that the visual experience is the process of understanding the world, the process of acquiring main perceptual experience and making judgements, the process of people gaining their own world view.

Every morning, when people wake up and open their eyes, huge visual information stimulate their mind, but few of people can calm down and think about the limitation of visual experience. Eyes, object, light source the three elements of a visual logic system. Any change may occur the change of visual experience. Let's imagine the possibility of generating a different visual experience in the same object and source case. Eyes can be of different species (human or animal), of different ages (the elderly or children), of be accidentally destroyed (strabismus or injury). Each subtle differences will bring out the different visual experience to the parties. If taking into account the factors of overlapping, the visual experience of the results will turned several times (imagine a colorblind animals hurt the eyes to see things). It is impossible to estimate all the possibilities of observation, because the various sunlight from different locations and time, variety combination of artificial light to object, expanding ability of observation by means and tools of telescopes, microscopes, periscope and cameras, video cameras.

Visual experience can be divided into two types: direct experience and indirect experience. Direct experience means experience obtained by observing the real object (sometimes using equipment like telescopes, microscopes). Indirect experience means acquiring visual experience through watching visual object information media, (like painting, photography, and video or computer virtual image). Visual object can be a real one or the information recording medium. Before the invention of photography, the accumulation of knowledge and development of technology is relatively slow, people get the visual information mainly from direct experience which leading people's action and thinking for a long period of time.

\section{Plane Pictures and Teaching Plane Picture DESIGN BASED ON VISUAL THINKING}

Visual image from one of the plane picture can accurately convey information content. Plane picture teaching and designing software (e.g.: Adobe Photoshop, Adobe Illustrator) with different plane figure involves visual thinking from 
design to application. From the point of view of teaching picture designer the teaching plane figure using in teaching possesses is better advantages than other information transmission way. And the perspective from audience (students), visual psychology controls the degree of accepting information to audience .For the information, in visual media design phase designer is to pay more attention to visual thinking factors, because the attention is often to achieve better result of the design and application effect .

\section{A. Visual Thinking Experience in the Plane Figure Design for Teaching Software}

The plane figure is one of the most commonly visual media. Vision sense is not only an intuitive feeling experience, but also a way of thinking. Thinking experience can be got through intuitive feelings. Visual media design depends on the ability and experience of visual thinking .Before designing for a specific object and theme, designer's mind will create many ideas quickly, and some of these ideas comes from inspiration, another from experience. Of course, author think more of them comes from experience, especially visual thinking experience. There are a lot of different experiences in visual thinking, people's experience difference is very obvious, but there be a common experience in different people, particularly for educates. (Students) At the same knowledge level layer, and in the same "lever layer" thinking experience, visual thinking is more common. In plane pictures teaching software design student's common experience in visual thinking is the primary consideration factor in design. Feeling of visual sense comes from the picture, the picture is layered in thinking, the various "layer" in the picture can be extracted so that forms some design elements. Even for the plane figure, the "layer" can be felt, very intuitive picture logic also can be felt, and directly access to the impact on the visual sense. Although the picture element is numerous, the author or designer will has arranged the layer elements in an orderly fashion through perspective method. It is easy to use the concept of "layer" to deconstruct these works. For a big picture, by cutting local part it can become the well independent one and one. Actually, using of "layer" now have not restricted in the plane picture screen. The $3 \mathrm{D}$ movie today is also another extension of the concept of "layer" in the visual sense.

Some experience of visual thinking is the experience of individual character, which is due to the experience of the individual from image thinking to abstract thinking is distinct different. Picture in the face of the visual thinking reflects in objective, real, concrete images and is provides with the education and aesthetic values with universal realistic significance and widely association.

Abstract thinking is often based on visual image thinking with both rational and exaggerated. At the same time abstract thinking is not limited by the object light, color changing, and the people's thinking and reverse thinking, harmony and the harmony. Under abstract thinking a stimulation, the feeling of exciting, association will be produced in human brain with the visual sense. In visual media design to the plane picture, rich experience or less experience from image thinking to abstract thinking play an immeasurable role to the design depth and connotation show and design level of plane visual media. And for another one, it is the knowledge of visual thinking and the acquired knowledge experience. The same object (plane figure) to different people, there is different thinking, (visual thinking) and there is different value of education and learning. However, for the basic education value there is great similarities to same plane picture which should be considered by teaching designer.

People's thinking is difficult to be controlled. Visual sense, plane picture design and application are often inspired, inducing factors of thinking, learning of knowledge and aesthetic ability can be changed with visual sense and visual thinking [6]. Common visual thinking and individual visual thinking exists in all visual thinking and common visual thinking objectively reflect the appearance of things, individual visual thinking can present deeply the designers' understanding and exhibition to visual media. Hence, plane picture design needs further consideration that the designed plane figure will produce what impact and function of thinking, which requires the designers to have rich experience in visual thinking [7], [8].

\section{B. Plane Pictures Teaching Software Design Requires Better Ability of Visual Thinking}

Plane picture design is a design and research field developing rapidly in recent years, especially in the education, teaching, advertising and promotion. The performance technology in unique visual space and psychological space on Plane picture design has promoted past experience from virtual experience to real experience. Its purpose is that the accurately convey information content through visual image

Visual media design on plane picture is recreation based on the visual thinking. To the ability of designing or recreating in addition to the above experience of visual thinking, designer must have self-discipline and hard efforts, unremitting pursuit and personal moment inspiration, and designer should have better ability of visual thinking as a result of good knowledge background. When facing with a design object of plane picture, imagery thinking, intuitive thinking and aesthetic intuition thinking enables designer to make their own unique understanding, judgment and summary to design objects. Based on the above design theory and idea designer will design better plane picture and plane picture teaching software.

When designing plane picture using teaching, the thinking caused by visual sense is mainly that the content displayed by plane picture is whether or not consistent with the teaching content, whether or not can be understood by learner easily, whether or not can be more effective to teaching and studying. For visual media design on the plane pictures more of thinking is not the image, the color of the text, deformation, etc. However, visual thinking for some visual picture design such as visual advertisement and plane advertisement media is much more complex. Because that involve pattern, color, lines, words and so on which will produce some psychological impact feeling and refer personal preferences. For the construction of the object in the plane figure design of visual media much more depends on the successful interpretation of the designer to design object, i.e. from the thinking experience to the new understanding and thinking to things. This new understanding and thinking is a good visual thinking ability. 
The good visual thinking ability to visual media design involves many factors, the most important factor is that extensive knowledge and good image thinking and abstract thinking ability. Encyclopedically knowledge, enable the thinking involved in the field of visual sense to is easy to understand visual object. A good image thinking and abstract thinking ability in media design can made the meaning of the picture, implied meaning to have enough depth and can cause more space for imagination and thinking. Of course, Forming of encyclopedically knowledge, good image thinking and abstract thinking ability needs long-term study and practice and gradually accumulation.

\section{CONCLUSION}

Plane picture is the most important visual media. Plane picture design depends on visual thinking, especially to teaching plane picture design. The designer to plane picture who would like to achieve better design effect needs to have enough experience and ability of visual thinking.

Visual media is the media of the visual delivery of information, it's one of the most abundant source of information. Visual media can be divided into the following categories: bit-mapped image, vector-based graphics, symbol, and volume graphics. Image and bit-mapped graphics vector-based are the most important visual media. As the plane design visual communication materials with visual signs, seek the best information in the appropriate combination of identification symbols and the originality of the convey combination.

The design of graphic rely on visual thinking, especially to get through the graphic design teaching.

Since education in China has long attached great importance in reading, writing and arithmetic. Teachers focus on developing student's capacity for language and logic, ignoring the visual thinking which can take a great part in students' growth and development. Visual language can make up for the limitation of verbal thinking, also help to stimulate creativity of students, greatly enhance the experience of them. Watching, thinking and painting can inspire the visual thinking of students which may increase visual resources, arouse educators and encourage students use the visual way to express their thoughts[9].

Experienced graphic designers is not necessarily the person who good at visual thinking. Experience can be accumulated from the relevant practical work, but visual thinking ability comes from personal experience, aesthetic and intellectual level, it's the combination of sense and sensibility [10].

Above all, a good teaching Plane Pictures Design base on

\section{Visual Thinking.}

\section{REFERENCES}

[1] W.-Y. Xu, "On the influence of thought and theory of classroom electronic courseware design on students thinking ability," Journal of Yunnan Open University, China, vol. 15, pp. 37-39, 2013.

[2] R. H. McKim, Experiences in Visual Thinking, Thomson Brooks, Cole, 1980, pp. 52-63.

[3] L. Zheng, "Talk about the design of visual elements to newspaper readability study," Master Thesis of Hunan Normal University, China, 2010.

[4] L-L. Gu and C.-M. wang, "Visual thinking in the application of multimedia courseware design," Modern Manufacturing Engineering, vol. 3, 2006.

[5] W.-Y. Xu, "Application of plane graph of image memory and knowledge construction in teaching," Journal of Yunnan Radio and TV University, China, vol. 13, pp. 21-24, 2011.

[6] HDT, "Visual communication design and visual thinking," Master Thesis of Suzhou University, China, 2004.

[7] S.-X. Fu, "Questions about visual thinking," Journal of Beijing University, vol. 36, 1999.

[8] American, Visual Thinking, Sichuan People's Publishing House, China, 1988.

[9] L. M. Shi, Computer Aided Mathematics Tutorial, Pudong Electronic Press, China, 2001.

[10] D.-Y. Liu, "The enlightenment of visual thinking to teaching," Journal of the Chinese Society of Education, vol. 2, 2010.

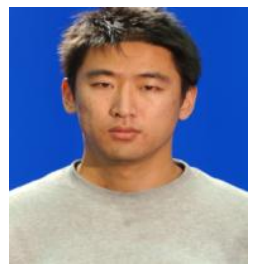

Xu Wenyi was born in Kunming, Yunnan, China, in 1978. He graduated with a degree of arts in advertising from Yunnan Normal University, China in 2001 and got his master's degree of education in education technology in 2011 at the same university. $\mathrm{He}$ once worked as a faculty of Education Technology Center in Beijing Union University, China from 2001 to 2006. In 2006, he was appointed as an associate professor with the Faculty of Media and Information Engineering in Yunnan Open University, China. The main articles and books: "On the influence of thought and theory of classroom electronic courseware design on students thinking ABILITY", Journal of Yunnan Rty University, Kunming, China, 2013, "Application of plane graph of image memory and knowledge construction in teaching", Journal of Yunnan Rty University, Kunming, China, 2011, "Premiere practice and application" Jiangsu Education Publishing. Ltd, China, 2011. His areas of experts are in graphic design and education.

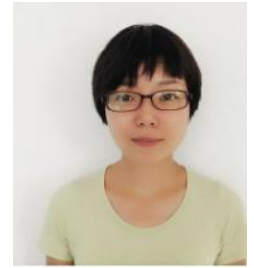

Li Jian was born in Kunming, Yunnan, China, 1978. She obtained her bachelor of arts degree in economics from Ocean University of China in 2000, and got her master's degree in law from Yunnan University, China in 2010. She was an employee of Bank of China from 2000, in 2015. She resigned to China Minsheng Banking Corp., Ltd. In 2015, she was appointed as a lecturer with the Faculty of Finance in Oxbridge College, Kunming University of Science and Technology, China. Her research field includes education, finance and economics. 